Dhaka Univ. J. Biol. Sci. 23(1): 9-16, 2014 (January)

\title{
INDOOR FUNGI ON DAMP WALLS OF BUILDINGS AND THEIR MANAGEMENT
}

\author{
SHABnAm SHAFA, S. SHAmsi AND M.A. BASHAR \\ Department of Botany, University of Dhaka, Dhaka-1000, Bangladesh \\ Key words: Fungicides, Damp wall, Indoor fungi, Bavistin, Tall
}

\begin{abstract}
A total of eight species of fungi and one sterile fungus were isolated from the indoor damp walls. The fungi were Aspergillus flavus Link, A. fumigatus Fresenius, $A$. niger van Teighem, A. niger (culture type 1), A. terreus Thom, $A$. terreus (culture type 1), A. ustus, Fusarium sp., Penicillium sp. Ulocladium sp. and a fungus with sterile mycelia. The frequency percentage of association of $A$. fluvus, A. fumigatus and A. niger was higher than any other fungi. This is the first report of association of fungi in indoor damp walls from the Department of Botany, University of Dhaka and a private house of Dhaka city. Effects of six fungicides were evaluated against the isolated fungi. Bavistin and tall were found most effective against the radial growth of the damp wall fungi.
\end{abstract}

\section{Introduction}

Fungal growth in damp buildings is an increasing problem, which has adverse effects on both the occupants and the buildings. The normal limit for rising damp ranges from 0.5 to 1.5 meters above ground level ${ }^{(1)}$. Excess moisture on almost all indoor materials leads to growth of microbes, such as mold, fungi and bacteria. Penicillium chrysogenum, Acremonium spp., Ulocladium spp. and Aspergillus versicolor are the most common fungal species in water-damaged buildings( ${ }^{(2)}$.

The negative health effects of damp building materials and fungal growth in homes, institutions, workplaces have been reported in many publications, including the WHO guidelines. The occupants of damp or moldy buildings are at increased risk of respiratory problems, respiratory infections, and the exacerbation of asthma ${ }^{(3)}$.

Use of fungicides provides excellent control of the wall from damping. Chlorine bleach is a fungicide that kills fungal spores on contact. However, just pouring bleach on fungal growth is not enough to reduce the risk of complications ${ }^{(4)}$. Therefore, it is necessary to test the efficacy of the fungicides against the targeted fungi.

In Bangladesh, the buildings are not properly built up and maintained. Weather conditions are also favorable for damping of the buildings. Most of the ground floor of the buildings are damp and ideal habitat for fungi which damage the buildings and also cause heavy financial loss to the owner. Although a lot of research have been done in many countries of the world by different investigators but no research investigation has 
been taken to detect the fungi associated with indoor damp wall. Considering the importance of buildings, financial loss and problems on human health, the present investigation was under taken to isolate, characterize and identify the fungi associated with indoor damp walls and the management of damp wall fungi with fungicides.

\section{Materials and Methods}

The materials of this investigation was the fungal colony associated with indoor damp walls of the Department of Botany, University of Dhaka and a private house of New DOHS within Dhaka City (Fig. 1). Samples were collected from the indoor damp walls during the period of May 2012 to May 2013. Room temperature and humidity was $19-32^{\circ} \mathrm{C}$ and $60-75 \%$, respectively.

The fungi associated with the collected samples were isolated following "Serial dilution plate method" in Potato dextrose agar (PDA) medium following the method of Greenberg et al.(5). Species of Ulocladium was isolated on $2 \%$ water agar medium supplemented with scraped wall ingredients. The indoor damp wall samples were also collected by sterilized scalpel and directly added to the molten PDA medium in the Petri plate. The plates were incubated at $25 \pm 2{ }^{\circ} \mathrm{C}$ for seven days in an incubator. The fungi growing out of the inocula were examined and identified whenever possible and preserved in the PDA slant medium. Per cent frequency of occurrence of the fungal colony were calculated by adopting the formula of Spurr and Welty(6).

Detail morphological studies of the fungal isolates were made in order to determine their identity. Identification of the fungal isolates was determined following the standard literature ${ }^{(7-11)}$.

Six fungicides were selected in the present study to observe their effect on the growth of the test fungi (Table 2). Efficacy of the fungicides were tested in vitro by poisoned food technique initially at $500 \mathrm{ppm}$ concentration ${ }^{(12)}$. Later bavistin and tall were also tested at 100, 200, 400 and 500 ppm concentrations against the test fungi.

The radial growth of the fungal colonies in the control and treatment were measured after five days of inoculation. The per cent growth inhibition of each test fungus was calculated by using the following formula:

$$
I=\frac{C-T}{C} \times 100
$$

where, $\mathrm{I}=$ Per cent growth inhibition, $\mathrm{C}=$ Growth in control and $\mathrm{T}=$ Growth in treatment.

Indoor damp walls were also sprayed with bavistin and tall at 500, 1000 and 2000 ppm concentrations. In case of control sterile distilled water was sprayed over fungal colonies on the indoor damp walls. After five days of treatment the fungi were isolated from the treated areas of the indoor walls by serial dilution plate method(5). The results were statistically analyzed by ' $t$ ' test following Steel and Torrie ${ }^{(13)}$. 


\section{Results and Discussion}

Aspergillus spp. was the predominating fungi associated with damp walls of Botany Department and the private house. It was frequently isolated from all the sampling areas of the present study. The fungus produced black colonies with effuse growth, The fungal species showed white to grayish cottony mycelial growth, forming white patches 8 - 10 inch in length and $5-8$ inch in width on the damp walls of the buildings (Fig. 1a, b). Ulocladium species showed blackish, effuse mycelial growth on the inner wall of the entrance of Botany Department nearer to a comfort room, 6 - 14 inch in length and 8 - 10 feet in width (Fig. 1c). Whitish, yellowish, pinkish and grayish patches of fungal colony up to 2 feet in height were also observed from ground level of the private house (Fig. 1d).
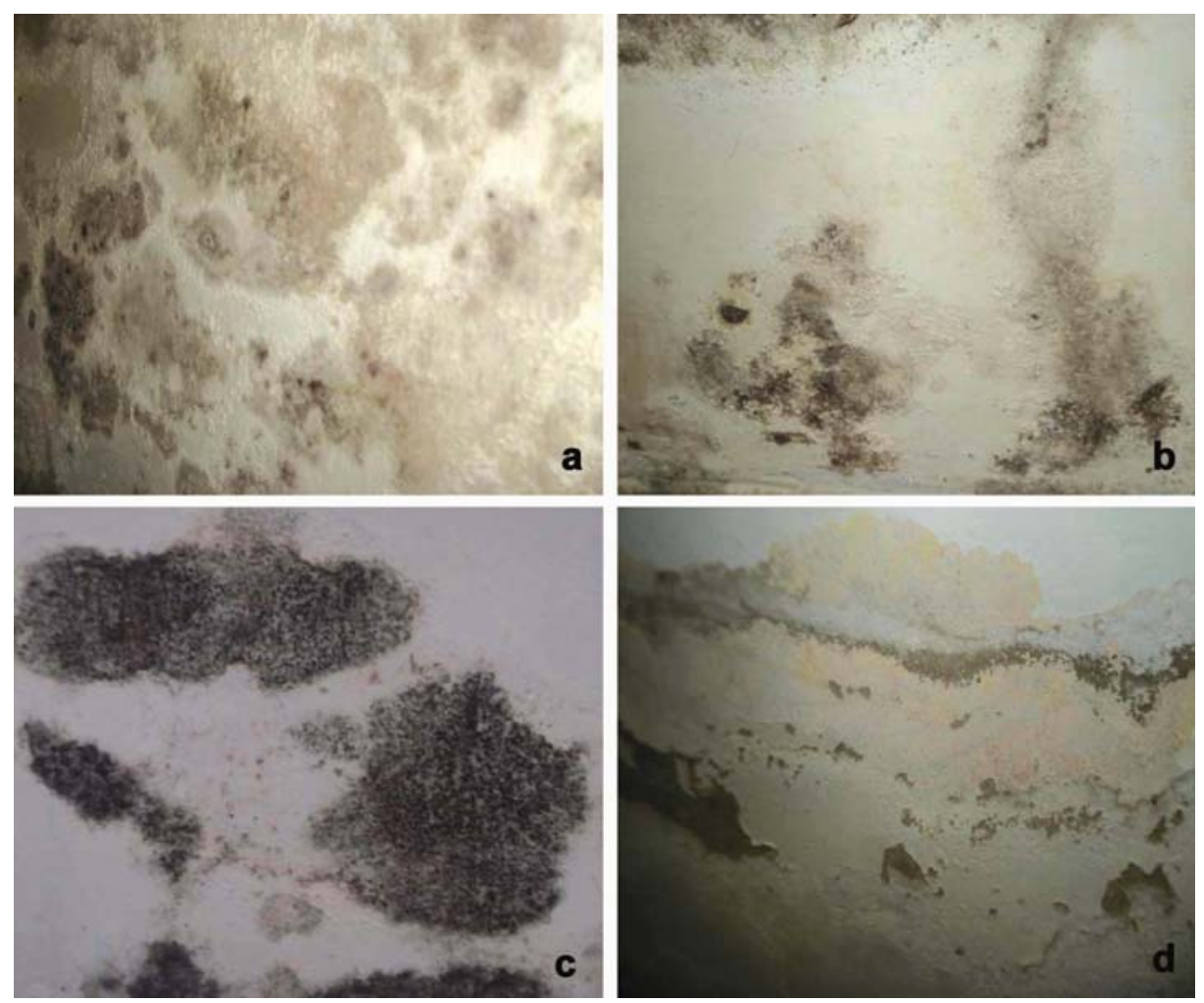

Fig. 1. Fungi on indoor damp walls of Botany Department, DU (a-c) and a house of Dhaka city(d).

Mean frequency percentage of association of fungi with indoor walls is presented in Table 1. A total of eight species of fungi belonging to 4 genera of Deuteromycetes were isolated from the indoor walls of the selected areas. The isolated fungi were Aspergillus flavus Link, A. fumigatus Fresenius, A. niger van Tieghem, A. niger (culture type 1), A. terreus, A. terreus (culture type 1), A. ustus, Fusarium sp., Penicillium sp., Ulocladium sp. 
and a sterile fungus. In order of their prevalence they were A. flavus, A. fumigatus, A. niger, Penicillium sp., Fusarium sp. and a sterile fungus. Their highest prevalence was $43.90,38.86,34.05,21.72,18.20$, and $3.02 \%$, respectively in the selected areas. Species of Ulocladium was the single fungus that was associated with the sampling area $\mathrm{C}$, round the year with abundant sporulation (Table 1).

Table 1. Mean frequency percentage of association fungi with indoor damp walls of Botany Department, DU and New DOHS.

\begin{tabular}{lcccccc}
\hline Name of fungi & \multicolumn{7}{c}{ \% frequency of fungi at different sampling areas } \\
\cline { 2 - 7 } & A & B & C & D & E & F \\
\hline Aspergillis flavus & 29.00 & 30.9 & - & 43.90 & 31.90 & 29.50 \\
A. fumigatus & 24.01 & 28.76 & - & 38.86 & 36.20 & 37.60 \\
A. niger & 31.70 & 33.44 & - & 26.16 & 26.00 & 34.05 \\
A. niger (culture type 1) & +09.61 & 09.68 & - & - & - & - \\
A. terreus & 08.51 & 12.20 & - & 03.80 & 03.98 & - \\
A. terreus (culture type 1) & +01.75 & - & - & - & - & - \\
A. ustus & 02.00 & 07.34 & - & 02.20 & 03.81 & 09.70 \\
Fusarium sp. & 04.58 & 03.32 & - & - & 10.65 & 18.20 \\
Penicillium sp. & 17.30 & 21.72 & - & 17.10 & 12.30 & - \\
Ulocladium sp. & - & - & 100.00 & - & - & - \\
Sterile fungus & - & 03.02 & - & - & - & - \\
\hline
\end{tabular}

'-' = represents no growth. A $=$ Office room, B = Ground floor and C = Inner wall of entranse of Botany Department; $\mathrm{D}=$ Ground floor; $\mathrm{E}=$ Ist floor and $\mathrm{F}=2^{\text {nd }}$ floor of a house, New DOHS, Mohakhali.

Maximum of seven species of fungi were found to be associated with office room of Botany Department. Prevalence of $A$. niger was the highest $(31.7+9.61=41.31 \%)$ followed by A. flavus, A. fumigatus, Penicillium sp., A. terreus, Fusarium sp. and A. ustus, showing the prevalence of $29.00,24.01,17.30,10.26(8.51+1.75), 4.58$ and $2 \%$, respectively (Table $1)$.

Eight species of fungi were isolated from the ground floor of Botany Department. The isolated fungi were A. niger, A. flavus, A. fumigatus, A. terreus, A. ustus, Fusarium sp., Penicillium sp. and a sterile fungus. Frequency percentage of association of $A$. niger was highest (33.44) and lowest was in sterile fungus (3.02) (Table 1). The results are in agreement with the findings of Anderson et al.(2). They reported the growth of Aspergillus fumigatus, A. melleus, A. niger, A. ochraceus, etc. on concrete and other floor-related materials.

Ulocladium sp. was the only fungus isolated from the inner walls of entrance of Botany Department during the period of the study. The frequency percentage of 
association of the fungus was (100). Association of Ulocladium spp., has been recorded on gypsum and wallpaper (2).

Six species of fungi were isolated from the ground floor of a private house. The isolated fungi were A. niger, A. flavus, A. fumigatus, A. terreus, A. ustus and Penicillium sp. Frquency percentage of association of $A$. flavus was the highest (43.90) and the lowest was recorded in $A$. ustus (2.20). In addition to Fusarium sp. same fungal species were also isolated from the $1^{\text {st }}$ floor. Frquency percentage of association of A. fumigatus was the highest (36.20) and the lowest was in A. ustus (3.81) (Table 1). The present findings are in agreement with the findings of McNeel and Kreutzer ${ }^{(14)}$. They reported the presence of Fusarium, Penicillium, Aspergillus and Stachybotrys chartarum on damp walls.

From the $2^{\text {nd }}$ floor five fungal species were isolated and they were A. niger, A. flavus, A. fumigatus, A. ustus and Fusarium sp. (Table 1). Frequency percentage of association of A. fumigatus was the highest (37.60) and the lowest was in A. ustus (9.70).

Among the six fungicides used in the present investigation, bavistin, indofil and acrobat are systemic while limi sulphur, tall and sulcox are protectant fungicides. The data with regard to their effect on the radial growth of the test fungi are given in Table 2. Efficacy of various fungicides against the test fungi in vitro indicates that bavistin, sulcox and tall showed promising results as compared to others.

Table 2. Per cent inhibition of radial growth of test fungi owing to fungicides at $500 \mathrm{ppm}$ concentrations.

\begin{tabular}{|c|c|c|c|c|c|c|c|c|c|c|}
\hline \multirow{2}{*}{ Name of fungicide } & \multicolumn{10}{|c|}{ Per cent growth inhibition of fungi } \\
\hline & Af & Afu & An & $A n^{1}$ & At & At 1 & $\mathrm{Au}$ & $\mathrm{F}$ & $\mathrm{P}$ & Sf \\
\hline $\begin{array}{l}\text { Bavistin } 50 \text { WP ( } 50 \% \\
\text { carbendazim (methyl } \\
\text { benzimidazol-2-ylcarbamate) }\end{array}$ & $100^{\mathrm{b}}$ & $100^{\mathrm{b}}$ & $100^{\mathrm{b}}$ & $100^{c}$ & $100^{c}$ & $100^{c}$ & $100^{\mathrm{b}}$ & $100^{c}$ & 47.0 & $100^{c}$ \\
\hline $\begin{array}{l}\text { Indofil M-45 ( } 80 \% \text { mancozeb } \\
\text { (Manganese ion + ethylene } \\
\text { bisdithio carbamate) }\end{array}$ & $51.7^{c}$ & $100^{\mathrm{b}}$ & $54.0^{c}$ & $80.9 c$ & $100^{c}$ & $70.1^{\mathrm{c}}$ & $72.0^{c}$ & $86.5^{\mathrm{a}}$ & $55.5^{c}$ & $50^{c}$ \\
\hline $\begin{array}{l}\text { Sulcox } 50 \text { WP (Copper } \\
\text { oxychloride) }\end{array}$ & $100 c$ & $100^{a}$ & $100^{c}$ & $66.0^{c}$ & $100^{c}$ & $100^{c}$ & $60.0^{c}$ & 05.71 & 75.0 & $100^{c}$ \\
\hline $\begin{array}{l}\text { Acrobat MZ (Dimethomorph + } \\
\text { mancozeb) }\end{array}$ & $50.0^{\mathrm{b}}$ & 03.57 & 45.31 & $33.75^{c}$ & $45.7 \mathrm{c}$ & $35.71^{c}$ & 42.1 & $31.42^{c}$ & $36.36^{c}$ & 17.39 \\
\hline $\begin{array}{l}\text { Limi Sulphur 80WP }(80 \% \\
\text { sulpher) }\end{array}$ & $18.7^{c}$ & $43.33^{c}$ & $38.88^{c}$ & $22.22^{c}$ & $38.88^{c}$ & $47.5^{c}$ & $37.03^{c}$ & 02.85 & $70.66^{\mathrm{b}}$ & $100^{\mathrm{b}}$ \\
\hline Tall 25 EC (Propiconazole) & $100^{c}$ & $100^{b}$ & $100^{b}$ & $100^{\mathrm{b}}$ & $100^{b}$ & $100^{b}$ & $100^{\mathrm{b}}$ & $100^{\mathrm{b}}$ & $100^{c}$ & $100^{\mathrm{a}}$ \\
\hline
\end{tabular}

Efficiency gradient: Tall $>$ Bavistin $>$ Sulcox $>$ Indofil $>$ Limi Sulpher $>$ Acrobat MZ. a, b and c indicate significance at 0.001, 0.01 and 0.05, respectively. Af = Aspergillus flavus, Afu = A. fumigatus, $\mathrm{An}=$ A. niger, $\mathrm{An} 1=$ A. niger 1 , At $=A$. terreus, $\mathrm{At}_{1}=A$. terreus $1, \mathrm{Au}=A$. ustus, $\mathrm{F}=$ Fusarium sp., $\mathrm{P}=$ Penicillium sp., $\mathrm{Sf}=$ Sterile fungus.

All the fungicides inhibited the radial growth of the test fungi. The extent of growth inhibition, however, varied amongst the test fungi. The complete inhibition of the radial growth of the test fungi was observed with bavistin except Penicillium sp. at 500 ppm. 
Bavistin caused $47 \%$ inhibition of the radial growth of Penicillium sp. at the same concentration. The complete inhibition of radial growth of all the test fungi was also recorded with tall (Table 2).

The growth of $A$. flavus, A. fumigatus, A. niger, A. terreus, A. terreus (culture type 1 ) and sterile fungus was completely checked with sulcox at $500 \mathrm{ppm}$ concentration. Sulcox was found to be responsible for $66,60,5.71$ and $75 \%$ growth inhibition of A. niger, A. ustus, Fusarium sp. and Penicillium sp. at the same concentration, respectively (Table 2).

The growth of $A$. fumigatus and $A$. terreus, was completely inhibited with indofil at $500 \mathrm{ppm}$. Indofil was responsible for $51.7,54,80.9,70.1,72,86.5,55.5$ and $50 \%$ growth inhibition of A. flavus, A. niger, A. niger (culture type 1), A. terreus, A. ustus, Fusarium sp. ,Penicillium sp. and sterile mycelium, respectively (Table 2)

The growth of sterile fungus was completely inhibited with limi sulphur. It was responsible for 18.70, 43.33, 38.88, 22.22, 38.88, 47.5, 37.03, 2.85 and $70.66 \%$ growth inhibition of A. flavus, A. fumigatus, A. niger, A. niger (culture type 1), A. terreus, A. terreus (culture type 1), A. ustus, Fusarium sp. and Penicillium sp., respectively. Acrobat MZ showed minimum growth inhibition against all the test fungi (Table 2).

Laboratory evaluation of fungicides revealed that all the fungicides caused partial or complete inhibition of the test fungi at $500 \mathrm{ppm}$. Similar observations have also been reported for other fungicides by other workers ${ }^{(15-17)}$.

Table 3. Per cent inhibition of radial growth of test fungi owing to fungicides at different concentrations.

\begin{tabular}{lccccccccccc}
\hline Name of & Conc. & \multicolumn{8}{c}{ Per cent growth inhibition of different fungi } \\
\cline { 2 - 11 } fungicide & $(\mathrm{ppm})$ & Af & Afu & An & An1 & At & At 1 & Au & F & P & Sf \\
\hline Bavistin & 100 & 100 & 100 & 100 & 100 & 100 & 100 & 100 & 100 & 33.0 & 100 \\
& 200 & 100 & 100 & 100 & 100 & 100 & 100 & 100 & 100 & 57.0 & 100 \\
& 400 & 100 & 100 & 100 & 100 & 100 & 100 & 100 & 100 & 75.0 & 100 \\
& 500 & 100 & 100 & 100 & 100 & 100 & 100 & 100 & 100 & 76.36 & 100 \\
Tall & 100 & 100 & 100 & 100 & 100 & 100 & 100 & 100 & 68.0 & 100 & 100 \\
& 200 & 100 & 100 & 100 & 100 & 100 & 100 & 100 & 77.14 & 100 & 100 \\
& 400 & 100 & 100 & 100 & 100 & 100 & 100 & 100 & 100 & 100 & 100 \\
& 500 & 100 & 100 & 100 & 100 & 100 & 100 & 100 & 100 & 100 & 100 \\
\hline
\end{tabular}

$\mathrm{Af}=$ Aspergillus flavus, $\mathrm{Afu}=$ A. fumigatus, $\mathrm{An}=A$. niger, $\mathrm{An}_{1}=A$. niger (culture type 1), At = A. terreus, $\mathrm{At}_{1}=A$. terreus (culture type 1$), \mathrm{Au}=A$. ustus, $\mathrm{F}=$ Fusarium sp., $\mathrm{P}=$ Penicillium sp., $\mathrm{Sf}=$ Sterile fungus.

Effects of different concentrations of bavistin on the radial growth of the test fungi is also presented in Table 3. Complete inhibition of the test fungi was noticed at all the tested concentrations except Penicillium sp. which showed partial inhibition of growth that is $33,57,75$ and $76.36 \%$ at 100, 200, 400 and 500 ppm, respectively. Tall also showed 
complete inhibition of growth of the test fungi at all the tested concentrations except Fusarium sp. which showed 68 and 77.14\% inhibition at 100 and 200 ppm, respectively (Table 3).

Bavistin and tall was sprayed on the infected wall of Botany Department, University of Dhaka and damp house of Mohakhali at 500, 1000 and 2000 ppm concentrations. After seven days the infection was found to disappear gradually with the increase of concentrations of bavistin and tall.

\section{References}

1. Halim AH and AZ Halim 2010. An Analysis of Dampness Study on Heritage Building: A Case Study Ipoh Old Post Office Building and Suluh Budiman Building, UPSI, Perak, Malaysia. 3: 4 .

2. Andersen B, JC Frisvad, IB Søndergaard, IBS Rasmussen and LS Larsen 2011. Associations between fungal species and water-damaged building materials. Appl. Environ. Microbiol. 77(12) : 4180- 4188.

3. WHO 2010. WHO guidelines for indoor air quality: Dampness and mould. Regional Office for Europe.

4. Hodge T 2011. What Kills Wall Fungus. http://www.ehow.com/info_12090175_kills-wallfungus.html

5. Greenberg AE, JJ Connors, D Jenkins and MAH Franson 1980. Standard Methods for Examination of Water and Waste Water (20 th ed.). APHA. Washington DC.

6. Spurr HW Jr and RE Welty 1972. Incidence of tobacco leaf mycoflora in relation to brown spot disease and fungicidal treatment. Phytopathology 62: 916-620.

7. Barnett HL and SB Hunter 1972. Illustrated Genera of Imperfect Fungi. Burgess Publishing Company, U.S.A., 3rd Edition. pp. 44-45.

8. Booth C 1971. The Genus Fusarium. Commonwealth Mycological Institute. Kew, Surrey, England.

9. Ellis MB 1976. More Dematiaceous Hyphomycetes. Commonwealth Mycological Institute, England.

10. Rapper KB and DI Fennel 1965. The Genus Aspergillus. The William and Wilkins Co., Krieger Pulb. Co. Huntigton, New York.

11. Rapper KB and CA Thom 1949. A Manual of the genus Penicillium. The Williams and Wilkins Co. Baltimore.

12. Johnson M and SC Sekhar 2012. Principles of Plant Pathology. Practical Manual. Acharya N.G. Ranga Agricultural University. Hyderabad, India. pp. 79.

13. Steel RGD and JH Torrie 1960. Principles and Procedures of Statistics. Mc Graw Hill Book Co., New York, pp. xvi +481.

14. McNeel VS, DVM Richard and A Kreutzer 2003. Mold and Indoor Air Quality. http:// healthandenergy.com/mold_and_indoor_air.

15. Goyal MK and RS Mehrotra 1981. Chemical control of root rot of gram caused by Rhizoctonia bataticola. Acta Bot. India 9: 228-232. 
16. Vishwakarma SN and KC Basu Chaudhury 1982. Laboratory evaluation of some fungicides against some root rot disease pathogens of gram. Phytopath. 35: 624- 627.

17. Bashar MA 1992. Laboratory evaluation of some pesticides on Fusarium oxysporum f. sp. ciceri causing wilt of chickpea. Bangladesh J. Bot. 21(1) : 157-159.

(Manuscript received on 12 September, 2013; revised on 12 December, 2013) 